\title{
Navigating the Canadian University System: An Exploration of the Experiences, Motivations, and Perceptions of a Sample of Academically Accomplished Black Canadians
}

\author{
Kevin Gosine \\ Brock University \\ E-mail:kgosine@brocku.ca
}

\begin{abstract}
This article reports findings from a qualitative study that explored the postsecondary schooling experiences, motivations, and perceptions of 16 high-achieving Black university students currently enrolled in or who have recently completed various high-profile university programs in Canada. While partly motivated to achieve the academic heights that they have by a desire for monetary reward and prestige, most participants were at least equally motivated by a desire to challenge racial stereotypes, be role models for Black youth, and put themselves in a position to improve the general situation of Black Canadians. There was considerable variation in how participants experienced the Canadian university system. Level of Black identification, gender, and field of study combined in unique ways in participants' lives to shape their schooling experiences and problematize the notion of an authentic or monolithic Black experience within the academy. In reflecting on the dearth of Black Canadians in prestigious university programs such as engineering, law, and medicine, most participants tended to downplay systemic explanations, emphasizing instead individual and community-based factors. Future research directions are discussed.
\end{abstract}

\section{Introduction}

North American universities have come under attack in progressive, left wing circles for maintaining White-normed, Eurocentric cultures where non-White faculty and students experience a sense of marginalization and exclusion (Bannerji, 1991; Beagan, 2001; Feagin et al, 1996; Henry et al., 2000; Henry and Tator, 1994, 2007). Critics argue a White-centred academic culture is perpetuated by factors such as Eurocentric curricula, a scarcity of non-White (particularly Black) faculty, incidents of both subtle and overt racism, and a general failure to implement effective equity and anti-racism policies and practices. A number of scholars (Carty, 1991; Bannerji, 1991; James, 1994, 1997) have observed the lack of recognition granted to racialized minorities and their histories in many Canadian universities. The Eurocentric emphasis within Canadian university curricula is a significant contributing factor to the underrepresentation of visible minority faculty, particularly within the humanities and social sciences. Indeed, Eurocentric perspectives and standards are given more status where hiring, promotion, and tenure decisions are concerned (Henry and Tator, 2007). Moreover, White privilege and systemic forms of exclusion remain embedded within the culture and institutional practices and procedures of the academy (Feagin et al., 1996; Henry and Tator, 1994, 2007).

There is considerable debate within the research literature that examines motivations of successful Blacks and the strategies they employ in negotiating racist social structures in order to 'make it'. Fordham (1988) has argued famously that a collectivist, counter-hegemonic ethos

Journal of Contemporary Issues in Education, 2007, 2(1), pp. 3-21.

ISSN 1718-4770 @ 2007 University of Alberta

http://ejournals.library.ualberta.ca/index.php/JCIE 
prevails within the African-American community that is not conducive to achieving success within a capitalist context that emphasizes individual initiative (see also Fordham and Ogbu, 1992). Fordham argues from ethnographic findings that African Americans who wish to achieve academic success and vertical mobility must adopt a "raceless" persona, that is, disassociate themselves from the African American community and conform to the standards of the dominant 'White' culture (see also Clark, 1991). On the other hand, there exists a body of literature suggesting that a salient Black identity and a corresponding sense of commitment to a Black community as a whole actually facilitates the achievement of mainstream success ideals. This research argues that 'successful' Blacks view personal success and the advancement of Black people as a collectivity as going hand-in-hand (Edwards and Polite, 1992). It has been found that many Black professionals view a strong Black identity as empowering and therefore insist on maintaining a sense of unity with other Blacks (Sampson and Milam, 1975; Miller, 1999). In a qualitative study of Black teacher candidates at Toronto's York University, James (1997) found that while participants experienced the university environment as largely exclusionary and oppressive, they nevertheless validated the system through their continued belief in the value and importance of a university education for Black Canadians. Rather than fighting for systemic change, these students emphasized hard work and determination for overcoming obstacles and were motivated by desires to challenge negative Black stereotypes and to become positive role models for Black youth. According to the research literature, factors that enable Black university students to navigate White-dominated university campuses include fostering connections with other Black students on campus, strong familial support, and positive relationships with and/or intervention by another person who is often an individual with some influence within the academic environment (Feagin et al, 1996; Williams, 2003).

In the face of prevailing critiques of the university, this exploratory study examines the university experiences, motivations, and perceptions of 16 academically accomplished Black Canadians currently enrolled in or who have recently completed high-profile university programs. The bulk of the research literature examines the experiences of Black students at the undergraduate level. Most of this literature has focused on Black students who struggle academically and/or find themselves disengaged from school (Kitossa, 1998). For this reason, I felt it worthwhile to explore the experiences and subjectivities of successful Black students who have studied in graduate and professional programs. I wanted to gain insight into the sorts of relationships that accomplished Black Canadians make with the university system. What factors have motivated them to pursue their education to the level that they have? To what extent have they experienced racist impediments or obstacles that critics highlight? If they have experienced such obstacles, I was interested in learning about strategies employed to overcome or survive these hurdles along with other challenges that come with the pursuit of a university education. Rather than generating definitive conclusions where this study topic is concerned, the goal of this article is to present some preliminary insights into the perceptions and lived experiences of high achieving, upwardly mobile Black Canadians and to highlight related areas in need of further research.

\section{Methodology}

In this research I employed a qualitative exploratory research design in which data were collected by way of in-depth semi-structured one-on-one interviews. The research is based on a purposive sample of 16 Black participants who, at the time that the research was conducted, were 
currently enrolled in or recently completed high profile, university-level academic and professional programs in Ontario. ${ }^{1}$ In addition, I sought participants who self-identified as Black and were Canadian citizens born in Canada or who lived here since the age of 12 or earlier. (Recent immigrants face a range of issues related to language, cultural adjustment, and differences in educational systems that lie beyond the scope of this study.) Finally, given my desire for individuals with recent experience within the Canadian university system, participants needed to have received all of their university training in Canada and be currently enrolled in or no more than one year removed from a university degree program.

Invitations were extended to potential study participants by contacting program directors and other staff at the University of Toronto and York University with a request that they post information about my research on faculty and departmental electronic mail list serves. I also approached Black student organizations such as the Black Medical Students' Association at the University of Toronto and the Black Law Students' Association at the University of Toronto and York University. Interested people were asked to contact me directly. Some of the initial participants obtained through these invitational measures put me in touch with other people they felt might be interested in participating in this research. Participants were guaranteed confidentiality and, in this article, pseudonyms are used when referring to study participants. Each participant was paid a $\$ 20(\mathrm{Cdn})$ honorarium for their participation..

As indicated above, the final sample consisted of 16 participants. Nine of these participants are female and seven are male. Thirteen were attending university at the time that they took part in this research and three had graduated within the year prior to taking part in the study. The mean age of the participants was 27.8 years with a range of eight years (24 to 32 years). Four of the 16 individuals in the sample reported being of mixed race parentage (i.e., one Black parent and one White parent). Five participants were born outside of Canada. ${ }^{2}$

Interviews lasted approximately 1.5 to 2.5 hours in length and, with the agreement of participants, were audiotaped and later transcribed verbatim. Questions were open-ended and designed to explore the following themes: educational background, experiences, and aspirations; social identity-related issues; educational achievement, and aspirations; and perception of Canada's opportunity structure. Interviews were conducted between August and December 2003.

My research objectives and questions were modified as the research went along based on the data generated during the research process. Data were collected and analyzed simultaneously. Codes for categorizing data were developed following analysis of the first few interview transcripts and modified over the course of the research. This process enabled me to develop themes and patterns to be gradually refined into an overall conceptual portrait of participants' perceptions and experiences. Finally, I conducted a member check in which I gave each participant the opportunity to verify her/his interview transcript as well as my research conclusions. ${ }^{3}$

\section{Findings}

\section{Motivation for pursuing goals}

Participants' narratives revealed an inherent tension that would seem to characterize the lives of many high achieving Black individuals who aspire to middle-class success ideals. On the one hand, as people who identify as Black, participants feel an obligation to improve the plight of 
Black people in general. Alongside this racially based collectivist ethos, however, is a subscription to the individualistic, meritocratic norms relating to personal success. When asked about their motivations for pursuing their education as far as they have, most identified a combination of racially based, collectivist reasons and individualistic factors. While most participants were willing to concede to the importance of achieving upward mobility, individual status, and financial security, two of the 16 participants unapologetically identified such individualistic factors as their primary motivation. One of these individuals, Phil, a 28-year old MBA student, explains: "we're not talkin' about, like, the 1930s or 40s where having a Black person graduate from university is a rare happening or occurrence, [so] I never looked at it that way, it was always just me personally graduating from university, as opposed to a Black person graduating from university." Troy, a 24-year old Ph.D. candidate in English, questions his capacity to serve as a role model for Black youth: "I don't think I'm gonna change any life based on being Black in academia. A low expectation, very low, but I think it's true, I think that's only fair to say." Troy and Phil do not identify with being Black as strongly as most of the others who took part in this research. These two individuals appear more heavily invested in the values of the dominant middle-class culture than any sort of imagined Black community.

In contrast with Phil and Troy, most participants, alongside individualistic or personal factors such as monetary reward and prestige, identified a sense of responsibility to Black Canadians as a salient source of motivation in their academic and career pursuits. Echoing findings by James (1991, 1997), these individuals viewed their accomplishments as a means of challenging prevailing stereotypes of Black Canadians as people who are intellectually less capable. As Allison, a 31-year old law school graduate recently admitted to the bar explains with clear emotion in her voice: "you're angry also that the person would think that you can't do it because you're Black, so it just makes you, you know, just push forward and just try even harder; so yeah, I mean again, a lot of time is spent and you may not be consciously aware of it, but a lot of time is spent trying to, you know, I'll show you, you know, prove someone wrong, you know, I could do this, I could do this!" In addition to deflating negative racial stereotypes, participants also expressed the desire to serve as role models for Black youth for whom they felt their success could serve an inspiration. Rachael, a 30-year old Ph.D. candidate, explains part of her motivation for pursuing a Ph.D.: "I'm hoping that at some point, at some time, the students of colour think that they too could go to grad school, they too can do this, and it's not just for those of the upper echelons of society or those who are White or those who are male, etc., so I'm hoping that I can affect students that way." Medical resident Steve, 31, echoes this sentiment when he explains that negative constructions of Blackness have "consciously driven me to excel and to sort of present a different picture than what maybe society's used to from a Black male, and also to show other Blacks that there are other options and other things in which they can be successful apart from media and sports."

Many participants were involved in Black student organizations that not only provided a sense of community for and addressed concerns of Black students currently enrolled in a given program, but also assisted prospective students in the preparation of applications and organized outreach ventures to elementary and high schools. Examples of such organizations include the Black Law Students' Association and the Black Medical Students' Association at the University of Toronto. Such organizations exist at other Ontario universities as well. 


\section{University experiences}

Much has been written about the White-normed and Eurocentric policies, curricula, and pedagogical approaches employed within North American universities that work to alienate or marginalize many non-White students (e.g., Feagin, et al, 1996; James, 1997). Where the participants in this study are concerned, narratives revealed considerable variability and ambivalence in terms of their experiences within the Canadian university system. How participants experienced their university education appeared to be contingent on a number of factors, most notably their level of Black awareness, gender, and their field of study. In general, with some exceptions, those in more quantitatively-based disciplines such as mathematics, the natural and physical sciences, and business, seemed to perceive the university environment as less hostile than students in the humanities, social sciences, and law. In reflecting on their university experiences, most science and business students complained about issues that would bother any tuition-paying university student, such as large, impersonal classes, faculty who seem to care little about teaching, and the pressure associated with being in challenging and highly competitive programs such as engineering and medicine. A notable exception to this general observation was Cindy, a 28-year old Ph.D. candidate in a science-related field at a Toronto university. This participant found the climate of her department to be a largely sexist one where "male professors [are] more condescending with the females. They wouldn't encourage you as much, not even giving you the same opportunities."

Medical student Helen, 25, noted having to contend with the occasional "stupid comment," such as the following stereotypical observation made by a medical school colleague of East Indian decent:

'Black people are so athletic and so sporty, like you know, Indian people are smart', and I'd be like oh, so, you know, I just asked her, are you saying Black people aren't intelligent, and she's like, 'well Indian people are like smart, like they tend to do better in school and stuff like that,' and I just told her off!

Helen, however, would seem to attribute this to misperceptions and ignorance on the part of a few aberrant individuals rather than racism that is systemically embedded in the fabric of the faculty environment. Most of the frustrations Helen expressed with medical school, such as the competitive nature of the program and the pretentious nature of people in the faculty, were not attributed to race. Among the 11 participants who studied mathematics, science, economics, or business at some level in their university careers, only one female articulated any sustained sense of discomfort in her program that was attributed to being Black. Julie, a 25-year-old master's candidate of mixed race, confesses to possessing an outgoing personality and corresponding sense of style that prevents her from fully relating to her colleagues in the medical sciences, whom she describes as "much more reserved, they're not as social as [Julie], they're not as outgoing." At the same time, she contends that the sense of alienation she feels because of this is exacerbated by the visibility that comes with being the only Black person in a predominantly White field. Explains Julie:

If you took a White girl with all the same attributes that I have, I don't think she would be punished as much as I am for wearing a tight top, or wearing makeup or whatever, or being giggly or loud or whatever it is. I think when you have those things and it's compounded 
by being Black, you know you, it's, it's so much more severe than if I were just, if I were, you know, 'WASP-y' or whatever.

Nine of the 11 participants who studied science and business related fields at some juncture in their university careers expressed an appreciation for the knowledge and skills acquired through their postsecondary schooling and, where their science and/or business training was concerned, had little to report in the way of blatant or subtle discrimination based on race. While many found the competitive nature of their programs to be stressful, participants expressed pride in being able to compete successfully in these high-status programs.

While most participants in the sciences and business did not perceive their universities as racist or oppressive, the same cannot be said for many in the social sciences and humanities. Participants who studied fields such as history, political science, and law expressed considerable sensitivity to what they perceived to be Eurocentric curricula, differential treatment from racially insensitive faculty, conservative, unprogressive academic environments that are generally unable to accommodate the diverse needs and interests of minority students, as well as conflicts with White peers. The lack of Black faculty in these institutions also troubled participants. Within such contexts, some participants reported a pronounced sense of marginalization and resultant discomfort within their respective institutions or programs. In relating her experiences at a Toronto law school, Allison clearly articulated her frustrations in this regard. This participant described a largely enjoyable undergraduate experience at the university where she later attended law school. As a history major who focused primarily on Caribbean and African history, Allison was impressed with the number of Black students at the school, the selection of courses, as well as what she perceived as a generally progressive atmosphere that prevailed within the institution. Her time at the law school housed at the same university, however, was a far less savory experience.

Although the law school was part of the same Toronto university where Allison enjoyed a worthwhile undergraduate education, she describes the law school as being different from the general university community. In Allison's words, the law school had a "conservative edge to it; the profession brings into play ego and competitiveness" that she found unsettling. Allison lamented the dearth of Black students and faculty at the law school as well as a curriculum that she describes as "painted with a White brush." Recalls Allison:

... Issues of race were rarely mentioned in criminal law. You spent an awkward two hours talking about it, you know what I mean? And that was it, and things weren't put in proper context. In terms of the courses that you had to choose, once you got into second and third year, and were able to choose more widely, the courses that dealt with issues of race and the law and all that kind of stuff. There was one course that you could take and that was African-Canadians and the law, that was it. Now I think the next year they had another course on, ah, race and something like that, or critical race theory and all of that kind of stuff, but there really weren't any other courses, there weren't even any other courses that dealt with, not only the Black community, but other communities.

For Allison, the law school environment was so oppressive that she felt "silenced," which she maintains "is ironic because I usually never feel that, I'm never silent; I kind of think of myself as a loud mouth in that I would, you know, something smells wrong or smells bad I'll say it, but I clearly remember in my first year of law school feeling silenced." Allison also expressed 
the frustration and pressure that came with taking it upon herself to represent 'Black' viewpoints in classes where she found the climate to be largely hostile to such perspectives.

Phoebe, 25, who at the time of our conversation was entering her second year of law school at another Toronto university, expressed similar anxieties about the environment at her faculty. As Phoebe explains in her effort to locate herself in the context of her faculty, "[ $t]$ he political orientation, I do not fit into it at all. It's very politically conservative, very right, I would say I'm quite left and it's kind of, like there are certain classes where I've had to write an essay and I've had to sort of screen what I would write, you know, taking into consideration my professor and his views and how he's gonna react to what I say." Like Allison, Phoebe reports feeling silenced, especially when....

.... They're talking about issues of race and things that come up and just hearing comments made in class that are just, it's just off the wall! And knowing that there's no one else in the class that, well, maybe there might be other people that are thinking about these issues the way that I'm thinking about these issues and then trying to decide okay, do I put my hand up, or am I just gonna sound like, am I just gonna be, 'oh, there's the little Black girl running around about her issues again,' you know. So you have to be wary of that, cause, I mean, me putting my hand up and saying something, they might not see it as credible as some White guy that puts his hand up and says the same thing. So there are times when I feel I don't belong there.

Phoebe's sense of how she is perceived within the law school environment relative to a typical White male student illustrates how race and gender often combine to create a double sense of marginalization for Black women within the academy (Bannerji, 1991; Carty, 1991). Two law school graduates, Aaron and Jane, 28 and 26 years of age respectively and both graduate students in law, recalled a tendency among some White students in their faculties to assume that Black students gained admittance through a special access program even though this was not the case with most Black law school candidates.

\section{Diverse experiences within the university}

In contrast with most previous studies that have portrayed race as the primary determinant of Black students' experiences within the university system, I found surprising variation amongst participants in terms of how they experienced the university environment, even among individuals who studied in the same institutions, departments, or faculties. One example would be the contrasting of experiences of Allison and Aaron, who attended the same law school. While Allison savored little from her law school experience, Aaron reported a positive experience at this same faculty:

Aaron: I loved it. I mean the, in terms of political and ideological culture, if you wanna call it that, this is my kind of place. The professors are very progressive minded and critical thinkers. I don't necessarily agree with all of them, but I love the fact that I can go into many classrooms, not all but many classrooms, with the professors here and hear discussions of class, race, gender, sexual orientation. Those kinds of issues that were foreign in most classrooms at [the university where Aaron took his undergraduate degree] really are important there. 
Interviewer: And are these the sorts of issues that have a fairly prominent place in the curriculum here?

Aaron: Yeah, I mean I don't wanna over-overstate the case, because you still find professors here who skirt those issues, right? And you know, my understanding is that this school has always had that tension between the professors who are very critical and those who are not, if you can make that kind of distinction. I think it does have an important place here, more so than in a lot of other schools.

While Aaron had high praise for his law school, which he currently attends as a master's candidate, his undergraduate experience at another Ontario university was a different story. Aaron, a history and political science major as an undergraduate, characterized his undergraduate institution in a way that was similar to Allison's description of the law school she and Aaron attended, as a "sea of conservatism" where "I didn't feel I could make a connection with a lot of [the faculty], or that they wanted to make a connection with me, particularly the ones in political science who were among the most conservative on campus." Aaron described an incident that occurred in the fourth year of his undergraduate program with a professor who had an irrational reaction to his request to revisit a term paper he had written for her class. As Aaron explains:

I had received a mark that I didn't like. I went to see her.]I was poised and I wasn't confrontational at all and within the first two sentences that came out of my mouth, she was automatically on the defensive, very threatened by me. I personally felt like I could see the fear of God in her eyes as people say, where she felt like I was gonna physically do something to her or, you know, she had that look in her eyes and she automatically said, 'I want you out of my office, can you leave, or else I'm gonna go get the Dean,' something to that effect, which to me was, I mean it really took me aback, because I hadn't, in my view I hadn't gone in there, I hadn't even raised my voice to be honest. But I felt like she was afraid of me for whatever reason and so I did, I left immediately. The Dean did come, she went to the Dean and the Dean came along and I waited to talk to the Dean and to kind of explain my situation so that he could see that I was not out of control or something to that effect.

Aaron's account of this encounter with a White female in a position of power invokes racist and gendered constructions of the violent Black male. When he paid a visit to the Dean to address this incident, the latter seemed content to dismiss the situation as quietly as possible, as he attempted to placate Aaron with an offer to write a letter of reference for him that is still in Aaron's possession. Aaron's experience demonstrates how universities, which frequently lack the structures to provide advocacy for the rights of students, often accept abuses of power or authority on the part of faculty (see Feagin et al, 1996). Even though Aaron brought the incident to the attention of the appropriate authority, the problem was not addressed in a just or appropriate fashion that would prevent a similar occurrence in the future. Although more sensationalized in nature than most of his undergraduate experiences, Aaron feels this incident to be representative of his time at this particular institution. In his words, it "really in some ways explained kind of the, the tension I had to deal with in my surroundings." Aaron's narrative also provided insight into how the insidious or camouflaged nature of systemic racism often creates a 
sense of insecurity and self-doubt in Black subjects, as one is often uncertain whether misfortune or negative experiences are due to racism or a lack of ability on one's part. While this he concedes, "I definitely know I have a bright future ahead," he confesses to having "bouts of insecurity." Confides Aaron:

I definitely go through that and I think for Black students, it's even worse because you're even more insecure about yourself. So when a professor, whom you respect and is your supervisor, but you can't get along with, you start to question yourself in different kinds of ways than people who probably aren't Black. Given the racism that exists in this society, you start to wonder whether it is racism or whether it's just they don't like you, and then you have these battles. I have these battles in my head all the time. So what I see as an obstacle is that tension in my head when I don't, I'm not successful in, you know, an application for a scholarship or for some school, but I know my work is good enough, you know, I always question, you know, does my resumé say something that makes me seem too Black? And should I care about that, should I care about changing my resumé? Or does somebody who's interviewed me, you know, just look at me as this Black kid who doesn't even deserve to be at their institution? I definitely wrestle with those things, or you know, this Black kid doesn't deserve that scholarship, there's other kids that, you know.... I think about that a lot.

It is interesting to note that, while Aaron found his undergraduate experience at this particular university to be a largely hostile one, two other participants who took undergraduate degrees from this institution - both in science related fields - found the environment to be more than hospitable. Helen, for example, obtained an undergraduate degree in mathematics at this university and had only positive things to say about the institution. While attending this school, in sharp contrast to Aaron, Helen found a supportive learning environment with "great" professors. In describing her relationship with faculty members at this university, Helen explains that she "would just go and hang out with them and just ask them tons of questions, any question I had and they would sit there with me and answer them cause no one else went there to ask for any help, so I did [laughs]." The contrast between Aaron's and Allison's experiences at the same law school, and between Aaron's and Helen's experiences at the Ontario university they both attended as undergraduates, illustrates that power and structure are never experienced in the same way by all Black people. How university environments are experienced by racialized subjects is contingent on the unique convergence of multiple factors, such as race, gender, class, field of study - to name merely a few influences.

As evident in the narratives of Allison and Aaron, reverberating concerns for participants in the social sciences and humanities were a lack of visible minority (particularly Black) faculty and Eurocentric curricula. While Allison was quite content with the undergraduate education she received at the Toronto university that she attended, Rachael, an anthropology major as an undergraduate student and currently pursuing a Ph.D. in a specialized social science field at this same institution, is highly critical of both her undergraduate and graduate experience at the university. Rachael colloquially describes the anthropology curriculum at this school as "very 'Whitified'," with a large emphasis on the works of White, male anthropologists and European theoretical perspectives. While the undergraduate anthropology program was dotted with course offerings on race and gender, she laments the fact that issues of racism, sexism, and associated power imbalances are not integrated into the curriculum in a more comprehensive fashion. She 
has found this situation to be much the same in the departments in which she pursued her graduate training. In both of these departments, she experienced difficulty locating faculty to supervise her work in the areas of race and gender. A significant source of motivation for Rachael in her pursuit of an academic career is her desire to challenge the White liberal feminist perspective that she sees as dominating her field and feminist thought generally by advancing, through her teaching and research, a critical stance that encompasses a "more integrated analysis of oppression." At the same time, Rachael worries about how her perspective will be received within her discipline: "I can see some tension there, I mean the usual stuff that academe brings, the sometimes problematic issues related to getting work published, I expect to face, you know, issues around that. So just that usual variety of stuff, finding issues, you know, whose work gets funded, why it gets funded, for how long, those things that, you know, I think a lot of us think about."

Rachael's charge of Eurocentricity in reference to the various departments in which she has studied at her Toronto university is echoed by Troy in his description of the English Department at another Toronto school. According to Troy, who is pursuing a Ph.D. in the same department from which he took his undergraduate and master's degrees, the Western literary canons that reflect the experiences, style, and subject matter of the European literary tradition dominate the curriculum of his department at all levels. Works by non-White writers are largely untreated in required courses at the undergraduate and graduate levels. Troy also majored in psychology in his undergraduate training and noted that issues of race and difference were also neglected in that department beyond a fleeting treatment in a social psychology course. What is interesting about this participant is that the Eurocentric nature of the curricula he has studied, or other issues such as a lack of Black faculty, did not bother him to the extent that they did other participants such as Aaron, Allison, Phoebe, and Rachael. Troy describes himself as not identifying very strongly with being Black and therefore has little interest in studying Black literature, issues, or topics. In the following quote, Troy addresses why the invisibility of Black authors in the English curriculum had little effect on him:

Well no, I didn't care much about it because you see, I wasn't and I'm still not very interested in Black authors and things like that. There are people in the department who, they're interested in Black authors and minority authors, female authors, of course, all of that stemming from their own identity. My identity was, I think sure without being racially conscious, you know? I went to a high school that was mostly White, it was a school that no Black person in my city wanted to go to. But I was comfortable there, I was comfortable also in university in a classroom like that, because I was never fully part of Black culture to begin with, you know, always on the fringes of it or ostracized by it, whether I did it myself or it was done to me, I don't know.

Like Troy, two other participants - Phil and Terry (a 29-year old law student) acknowledged but seemed to take little issue with the fact that race or diversity-related topics were given scant attention in the various university programs in which they studied. These individuals were similarly unaffected by other factors that some study participants found problematic, such as a lack of Black faculty and students. Once again, such variation in perceptions and attitudes illustrates that race is not the ultimate source of experience for all Black subjects, as high-achieving Black people experience dominant social and political contexts differently depending on the relationships they make with Blackness, gender, Canadian society, 
and middle-class culture, along with the field in which they study or work. For example, the few participants who identified little with being Black and strongly with middle-class achievement values found the university more hospitable than those who considered Blackness to be a salient component of their identity. In addition, as noted above, participants who studied more quantitatively-based disciplines were less critical of their programs than those in social science or humanities fields. Finally, female participants on the whole articulated more pronounced instances of frustration and hardship within the academy than their male counterparts, with Allison, Cindy, Julie, Phoebe, and Rachael being prominent examples. Gender, then, appears to exert a significant influence on how Black university students experience the academy. In all, because different social statuses such as race, gender, and disciplinary association combine in unique ways in people's lives, social actors bring different meanings and expectations to the contexts that they inhabit.

\section{Sources of perseverance}

Participants identified a number of factors that helped them to negotiate the various challenges of university life, most notably support from family, from some of the faculty at the universities they attended, and peers, particularly Black peers. For some, family was an important source of encouragement and support. Family was credited with providing the psychological tools necessary to cope with the racism some individuals experienced within the university. A few participants identified supportive faculty members and supervisors who offered them the encouragement and help that enabled them to persevere and succeed. Some participants reported forging close relationships with one or more of the few Black professors or teaching/lab assistants in their university, faculty, or department. In many of these cases, the traditional instructor/student boundaries were blurred as Black faculty frequently went above and beyond the call of duty to mentor Black students, in some instances treating them to visits to their homes along with other such outings. Some participants reported close ties with non-Black faculty and role models who helped them to acquire the skills and knowledge that they desired.

More than anything else, participants identified peer support within the university as a crucial source of perseverance, particularly Black peer support. Along with the reputations of schools and programs, almost all participants identified the ethnocultural diversity of the student body as a key criterion for selecting their undergraduate university. As Feagin et al $(1996$, p. 75) observe, "the anxiety and fear generated by being a Black person in a mostly white university is mitigated by the presence and support of other Black students." Sticking together enables Black students to survive in a White-dominated, Eurocentric context "without feeling completely powerless" (Feagin et al, 1996, p. 74). The accounts of participants in the present study, particularly those who reported experiencing race-related difficulties within the university, confirm this contention regarding the importance of Black peer groups. Jane, for example, describes the Ontario law school she attended as very much a White-normed, conservative institution where she did not always fit in. She describes how the few Black students in the Faculty inevitably stuck together: "A lot of people that I went to law school with at [University $\mathrm{X}$ ] actually went to [Jane's undergraduate institution] and I had no idea who they were, just because everyone's used to their own little clique; but when you go to a place like [University $\mathrm{X}$ ], where there's like 10 Black students, well, you're gonna join together [laughs] because that's all you have." 
In discussing her experiences at the institution where she took her undergraduate and law degrees, Allison notes that she "consciously sought out, you know, Black people, like to experience more Black friends and so forth." This participant elaborated on the important role that Black peer support played in her university career:

I threw myself into my experience at [University $\mathrm{X}$ ] and making connections with other Black people and sharing experiences and things of that sort, cause I realized that there was a connection there ....there were certain commonalities of experience that we could relate to, that I did not have when I was in high school. I kept, you know, some of those friends from [University X], they remain my good friends to this day. In law school, again I, you know, you have to seek out, well not really seek out, you kind of just came together, because you just pool together because, you know, there's strength in numbers and for support.... a sense of banding together in order to kind of get through this three year ordeal.

Allison's notion of "commonalities of experience" furnishes the basis of defensively situated, intersubjective racialized identities constructed by Black students in White-centered universities, departments, and faculties. Such collective racial identities to some degree suppress intra-group differences and serve as a protective mechanism against the marginalization and exclusion Black students feel within the university context. Such transcendent Black identities are evident in Black student organizations with which many participants were involved, such as the Black Law Students' Association and the Black Medical Students' Association. These organizations provide many Black students with a sense of solidarity and support that enable them to overcome various obstacles and challenges. Such obstacles and challenges include everything from assistance with program-related material to tackling and coping with perceived racism. Allison describes the important role the Black Law Students' Association played in helping her to persevere through a trying educational experience at law school:

Without a doubt, I would have to say thank goodness for the Black Law Students' Association, thank goodness, thank goodness! We were just so enthusiastic about being in law school, but you know we quickly learned, you know, about some of the hardships there, but we were happy to be together doing this and happy to meet other Black students in other provinces doing the same thing. So that organization, I tell you, literally saved me, and the friends that I formed in law school who were also in that organization remain my good friends to this day.

\section{An Ambivalent view of collective Black identities and Black student organizations}

While Allison trumpets the merits of Black student organizations of this sort, other members are more ambivalent. Emil, a 31-year old student who currently attends the law school from which Allison graduated and is a member of the Black Law Students' Association, raises concerns about the appeal to a bounded essentialism that underpins the organization:

Yeah, just, kind of playing devil's advocate and I guess there are, you know, there are points for and possibly against it. I think, right now, it's a necessary mode of getting people together and the problem is, I mean, Black people in general are so diverse 
culturally, like what does it mean to have a Black students' association? I remember at [Emil's undergraduate university] we had a Black students' association and there was a culture show. There was an Egyptian that wanted to be in the show and there was an issue with her being in the show, because they didn't consider her Black, and I thought that was ridiculous! That's an example of some of the issues that come up when you start talking about Black student associations. How do you define that? The social events and so forth are, I think are great, but I don't know how important they are in the grand scheme of things. I think where an association like this has value is that they're the ones that can go back to the community and outreach to kids, cause nobody else is gonna do that and, it's in our best interest to do that and I don't think there's any other group on campus that's gonna focus specifically on that group. And just networking and so forth, which is, which is a great, support structure. But I think too, you know, there are arguments against it also. But I think the pros outweigh the cons at this point.

Emil expresses concerns about where the boundaries are drawn to demarcate who belongs and does not belong in a Black student organization. Emil's narrative, particularly the anecdote about he controversy surrounding an Egyptian student's desire to participate in a Black cultural event at his undergraduate university, illustrates that there is never consensus or closure regarding what constitutes a Black identity. What it means to be Black is constantly argued or negotiated, despite attempts by Black groups to project knowable and bounded collective identities as a basis for community and activism. With the concerns that he raises in the above quotation, such as the exclusionary way in which 'Black' is defined for the purposes of a Black student organization, and his characterization of efforts to exclude the Egyptian student from the cultural event as "ridiculous," Emil seems to imply that essentialist and closed collective identities that furnish a basis for Black organizations are ultimately arbitrary and tenuous. While critical of the Black Law Students' Association's attempt to construct a recognizable and bounded Black identity and sociopolitical outlook, however, Emil concedes to the importance of the organization for its community outreach activities and as a source of support for current and prospective Black students in the context of a White-normed faculty. The narratives of participants such as Allison and Emil, then, illuminate a central tension within marginalized groups where community organizing is concerned: the perceived need for essentialism versus the acknowledgement and accommodation of difference.

\section{Faith in the system}

In identifying factors that might explain the paucity of Black students in prestigious university programs, most participants cited class-related factors (i.e., a lack of financial resources and middle-class role models), insufficient cultural emphasis on education within Black communities, the lack of Black role models in their fields, and a "lack of encouragement," with the latter phrase coming up repeatedly in conversations with different participants.

Only a handful of individuals (primarily participants with a social science background) seemed to possess a language to articulate the idea of systemic or institutionalized racism that stands taller than individual failures and micro-level interventions, identifying in particular the systematic streaming of Black students at the high school level into non-academic courses or tracks as well as away from math and science courses. The narratives of most participants, some more explicitly than others, revealed a general faith in Canadian universities as genuine, 
meritocratic systems. Indeed, the dominant argument among most interviewed seemed to be that if we correct for economic and social capital-related factors, provide suitable (i.e., Black) role models and mentors, and proper encouragement is provided from the right individuals, Black Canadians will be brought to the same starting line as Whites, thereby positioning them to run a largely fair race. By contrast, a minority of participants sees the racetrack as lined with greater hurdles for some groups of people. Rachael nicely sums up the latter stance:

I would not tell any of my students of colour, or not, that, you just work hard and you can do it, because you very well may work hard and you very well might still not be able to achieve what you wanna achieve, because of systemic barriers that are very much pervasive in our society. So until we can kind of navigate and work through that and change, not us per se, but until those systems of dominance and hegemony are changed, you could work your ass off and really still not get what you deserve per se.

As James (1991, 1997) found in studies of Black high school students and Black university teacher candidates, the dominant means identified by study participants for overcoming perceived obstacles was that of working hard, individual perseverance, and having the 'right attitude.' Other participants stress the importance of setting personal goals and working hard to achieve them. Helen highlights this strategy as a means of achieving her goals within the medical profession: "I know that there's racism out there but I know how to deal with it; I know when it's there and I know what's the best way to get around it, and my goals are to get to where I need to be and then help others get there too, you know?" A recurring theme was the need for participants to "prove themselves" in order to demonstrate that they deserve a place their chosen fields and professions. Although my findings differ from James's (1997) study of teacher candidates at York University in that not all of my research participants "questioned the basis of the merit system used to assess them" (p. 166), our findings converge in that, as in James's study, virtually all of my participants seemed to employ the individualistic values of this merit system as a means of overcoming perceived obstacles.

\section{Conclusion}

Two primary findings emerge from this study. First, Ontario universities still have work to do in terms of developing curricula and pedagogic practices that validate the lived experiences of an increasingly diverse student body as well creating a more inclusive and equitable academic environment. Second, where Black Canadians in the university system are concerned, it is not possible to talk about an authentic Black experience or outlook. By and large, participants were motivated to pursue their education to the level that they have by a combination of two factors. On the one hand, most of the individuals I spoke with conceded, to varying degrees, to being motivated by individualistic factors such as status, power, and monetary reward. At the same time, contrary to Fordham's (1988) "racelessness" thesis, most of the individuals studied were pushed by a desire to help other Blacks by serving as successful roles models and mentors, participating in Black student organizations, and challenging negative racial stereotypes. In addition, participants expressed a determination to prove themselves and demonstrate their merit. For most participants, being Black along with the accompanying sense of commitment to Black people seem to provide a buffer against the competitive, individualistic ethos of the broader 
capitalist society. This racial identity furnished individuals with a sense of responsibility, community, and belonging.

There was considerable variation among participants in terms of their experiences within the university system. By and large, participants in natural and physical science fields and business found their experience within Ontario universities to be more hospitable than students in the humanities, social sciences, and law. Most participants in the latter fields reported being troubled by a lack of Black faculty and students in their programs as well as what they perceived to be a generally White-normed or Eurocentric academic culture that paid little attention to antiracist and anti-oppression perspectives. Where Black university students or graduates are concerned, the apparent relationship between the way the university environment is experienced and field of study can perhaps be explained by the fact that those in humanities and social science disciplines have explicitly studied issues related to race, gender, and inequality, and are therefore instilled with a heightened sensitivity or critical consciousness where these issues are concerned. There could also be a greater expectation on the part of humanities, social science, and law students that their disciplines will tackle such issues as opposed to 'hard' science fields which are constructed as having a neutral or apolitical detachment from the social, political and economic realms. In all, where the university system is concerned, it is clear that we cannot talk about a uniform or authentic Black experience. How Black students experience the university environment (or any context) is contingent on the unique intersection of a number of factors: the extent to which individuals identify with being Black, gender, and the subject area studied were the major influences highlighted in the narratives of those who participated in this study. Further and more extensive research on Black Canadian university students would undoubtedly unveil other factors. The complex interaction of such identity-related influences makes it difficult (if not impossible) to generalize with credibility the experiences of Black Canadian university students.

A final observation of interest has to do with the way participants think about issues of racism and racial inequality. Most of the individuals with whom I spoke did not critique university practices, policies, and standards, which they accepted as a fair measure of individual merit. Schenke (1993, cited in James, 1997, p. 160) argues that such acceptance of the merit system of the university "regardless of social difference, obscures the recognition of institutionalized racism and historic and systemic practices of exclusion." Only a minority of participants in the present study seemed to conceptualize racial inequality in education in systemic or institutionalized terms. In explaining the scarcity of Blacks in prestigious university programs, most participants stressed popular right wing factors for explaining racial inequality, such as intra-communal influences, the absence of viable self-help networks, and a lack of mentors and role models. For most of the individuals studied, racial inequality could only by ameliorated on two levels: the individual level and the communal level. Many did not see a need for change at the systemic level of the university, as the amelioration of racist obstacles was envisioned primarily within the context of the existing educational system and larger sociopolitical order (for example, the establishment of Black self-help groups and organizations, and training themselves to be mentors and role models). Participants were largely optimistic about their professional futures, as they were very ambitious and saw considerable opportunities. While many pointed to racism as a potential obstacle, once again, most individuals tend to perceive this phenomenon in individualistic rather than systemic terms. Participants were optimistic that such roadblocks could be overcome and championed individual hard work and determination as the primary means of overcoming them. 
This exploratory study highlights two areas that require greater scholarly attention in Canada. First, while the antiracist paradigm has rightly encouraged much attention to be focused on the structures and processes of schooling, relatively little attention has been devoted to understanding the influence of class dynamics in explaining Black academic underachievement. Insofar as Blacks lag behind Whites and other racialized groups in Canada in terms of socioeconomic status (see Mensah, 2002; Ornstein, 1997), the role that class-related factors play in shaping the relationships that Black youth make with the educational system along with their career aspirations needs to be examined more thoroughly than it has been to date. Just as the present study has explored the ways in which middle-class culture shapes the identities, experiences, and aspirations of Black Canadians, similar research is needed that specifically focuses on the influence of working-class culture in this regard. Where the influence of class dynamics is concerned, research that compares working-class Blacks with working-class individuals of other racialized statuses, and working-class and middle-class Blacks, would undoubtedly yield invaluable insight into the factors that impede and facilitate Black educational achievement. Second, research is needed to explain the dearth of Blacks studying in quantitatively based fields (i.e., mathematics, physical science disciplines, engineering, and medicine) at the university level. While the paucity of women in such fields has been widely discussed and written about, the scarcity of Black students in these disciplines has received scant research attention. If scholars, educators, activists, and policy makers wish to mitigate racial inequalities in occupational status and income in Canada, it is imperative that the factors contributing to the absence of Black Canadians in such high profile fields be understood.

\section{Acknowledgements}

The author is indebted to Lorna Erwin, Carl James, Gordon Pon, and Lisa Taylor for their thoughtful and constructive feedback on earlier drafts of this manuscript.

\section{Notes}

1. For the purposes of this research, a 'high profile' university program of study refers to one that prepares students for an occupation that is considered financially lucrative and/or that is socially constructed in a way that it carries significant prestige within Canada and other Western societies. Such occupations include medical physician or surgeon, dentist, university professor, lawyer, banker, engineer, or any occupation that requires a Master of Business Administration (MBA) degree. In addition, in the interest of studying individuals who can be considered 'highly educated', I was only interested in participants whose current or last degree completed requires, in whole or in part, a first degree at the university level.

2. Aubrey, Cindy, Helen, Rachael, and Troy were born outside of Canada. Helen and Rachael were born in England; Aubrey, Cindy, and Troy were born in Jamaica, Guyana, and Trinidad respectively. The mean age at which these five participants arrived in Canada was seven years with a range of 10 years $(12-2)$.

3. On 6 January 2005, each person was sent via electronic mail her or his interview transcript and a penultimate draft of the doctoral dissertation from which this article emerged. Fifteen of the 16 individuals who took part in this study received these materials. The contact information for one participant, Jane, changed without my knowledge and I was therefore unable to send the items to this individual. 


\section{Appendix Participants}

\begin{tabular}{|c|c|c|c|c|c|}
\hline Participant & Age & $\operatorname{Sex}$ & $\begin{array}{l}\text { Degree held or } \\
\text { currently pursued }\end{array}$ & Country of birth $* *$ & $\begin{array}{l}\text { Currently in } \\
\text { school }\end{array}$ \\
\hline 1. Aaron & 28 & M & Master of Laws & Canada & Yes \\
\hline 2. Allison & 31 & $\mathrm{~F}$ & Bachelor of Laws & Canada & No \\
\hline 3. Aubrey & 32 & $\mathrm{~F}$ & $\begin{array}{l}\text { Master of Business } \\
\text { Administration }\end{array}$ & Jamaica (8) & Yes \\
\hline 4. Cindy & 28 & $\mathrm{~F}$ & Ph.D. (Science) & Guyana (3) & Yes \\
\hline 5. David* & 24 & M & M.Sc. (Science) & Canada & Yes \\
\hline 6. Emil & 31 & M & Bachelor of Laws & Canada & Yes \\
\hline 7. Helen & 25 & $\mathrm{~F}$ & Medical Doctor & England (12) & Yes \\
\hline 8. Jane & 26 & $\mathrm{~F}$ & Master of Tax & Canada & Yes \\
\hline 9. Julie* & 25 & $\mathrm{~F}$ & M.Sc. (Science) & Canada & Yes \\
\hline 10. Phil & 28 & M & $\begin{array}{l}\text { Master of Business } \\
\text { Administration }\end{array}$ & Canada & No \\
\hline 11. Phoebe & 25 & $\mathrm{~F}$ & Bachelor of Laws & Canada & Yes \\
\hline 12. Rachael & 30 & $\mathrm{~F}$ & Ph.D. (Soc. Science) & England (2) & Yes \\
\hline 13. Steve & 31 & M & Medical Doctor & Canada & No \\
\hline 14. Terry* & 29 & M & Bachelor of Laws & Canada & Yes \\
\hline 15. Tracy* & 27 & $\mathrm{~F}$ & Medical Doctor & Canada & Yes \\
\hline 16. Troy & 24 & M & Ph.D. (Humanities) & Trinidad (10) & Yes \\
\hline
\end{tabular}




\section{References}

Bannerji, H. (1991). Racism, sexism, knowledge and the academy. Resources for Feminist Research, 20(3/4), 5-18.

Beagan, B. (2001). Microinequalities and everyday inequalities: Race, gender, sexuality and class in medical school. Canadian Journal of Sociology, 26(4), 583-610.

Carty, L. (1991). Black women in academia: A statement from the periphery. In H. Bannerji, L. Carty, K. Dehli, S. Heald, \& K. Himmanji (Eds), Unsettling Relations: The University as a Site of Struggle (pp. 6-13). Toronto: Women's Press

Clark, M.L. (1991). Social identity, peer relations, and academic competence of AfricanAmerican adolescents. Education and Urban Society, 24(1), 41-52.

Edwards, A., \& Polite, C.K. (1992). Children of the dream: The psychology of Black success. New York: Doubleday.

Feagin, J.R., Vera, H., \& Imani, N. (1996). The agony of education: Black students at white colleges and universities. New York: Routledge

Fordham, S. (1988). Racelessness as a factor in black students' school success: Pragmatic strategy or pyrrhic victory. Harvard Educational Review, 58 (1), 54-84.

Fordham, S. \& Ogbu, J. U. (1992). Black students' school success: Coping with the burden of "acting white". In J.J. Macionis \& N.V. Benokraitis (Eds.), Seeing Ourselves: Classic, Contemporary, and Cross-Cultural Readings in Sociology (pp. 287-303). Englewood Cliffs, N.J.: Prentice Hall.

Henry, F. \& Tator, C. (1994). Racism and the university. Canadian Ethnic Studies, 26(3), 7490.

Henry F., \& Tator, C. (1997). Through a looking glass: Enduring racism on the university campus. Academic Matters: The Journal of Higher Education, February, 24-25.

Henry, F., Tator, C., Mattis, W., \& Rees, T. (2000). The colour of democracy: Racism in Canadian society $\left(2^{\text {nd }}\right.$ Ed.). Toronto: Harcourt Canada.

James, C.E. (1991). Making it: Black youth, racism and career aspirations. Oakville, ON: Mosaic Press.

James, C.E. (1994). The paradox of power and privilege: Race, gender and occupational position. Canadian Woman Studies: Race and Gender 12(2), 37-51.

James, C.E. (1997). Contradictory tensions in the experiences of African Canadians in a faculty of education with an access program. Canadian Journal of Education, 22, 158-174.

Kitossa, T.K. (1998). Image, identity, and experience in the educational encounter: Life histories of four African Canadian men. Master's Thesis, Faculty of Education, York University.

Mensah, J. (2002). Black Canadians: History, experiences, social conditions. Halifax, N.S.: Fernwood.

Miller, D.B. (1999). Racial socialization and racial identity: Can they promote resiliency for African American adolescents? Adolescence, 34, 493-501.

Ornstein, M.D. (1997). Report on ethno-racial inequality in Metropolitan Toronto: Analysis of the 1991 Census. Access \& Equity Centre of the (former) Municipality of Metropolitan Toronto.

Sampson, W.A. \& Milam, V. (1975). The intraracial attitudes of the Black middle-class: Have they changed? Social Problems, 23, 153-165. 
Williams, B. (2003). Charting the pipeline: Identifying the critical elements in the development of successful African American scientists, engineers, and mathematicians. Doctoral Dissertation, Division of Education Studies, Emory University. 